\title{
Editorial
}

\section{La globalización: la nueva ideología de dominación del capital1}

Hablamos del capital para referimos de manera breve a sus propietarios, pero sobre todo para destacar cómo esa "cosa", convertida en una relación social, los posibilita a ellos, a sus dueños, a tener dominio sobre nuestras vidas.

Hasta hace algunos años cualquiera hubiese refutado con indignación el título de este comentario y se habría alegado, con razón, que si bien el capital dominaba a algunos estados nacionales pequeños, e inclusive a algunos medianos, no los dominaba a todos... pero, ¿se podrá decir lo mismo ahora?

En la actualidad, el Acuerdo Multilateral sobre Inversiones (AMI) establece que los inversionistas y las empresas transnacionales pueden demandar judicialmente a los gobiemos por la disminución de sus beneficios, a causa de políticas o acciones públicas emprendidas por los mismos. Con esta potestad ya no cabe ninguna duda de la dominación absoluta del capital sobre los Estados Nacionales. ¡Que parece increible! Cierto, pero es real. Que parece injusto, quizá, pero la justicia y el dinero no caminan de la mano. Razón por la cual "los derechos son de los inversores y sus empresas y las obligaciones para los gobiernos".

El AMI es un documento elaborado secretamente en el seno de la Organización de Cooperación y Desarrollo Económico (OCDE), que agrupa a los principales países industrializados y se viene negociando discretamente desde 1995. Los 29 integrantes de la OCDE esperan ponerse de acuerdo entre sí sobre los términos del documento, para luego hacerlo cumplir de manera obligatoria a los restantes países del mundo, incluyéndonos, por supuesto, a nosotros los subdesa- 
rrollados. Una vez que se firme este nuevo tratado internacional, los gobiemos del mundo estarán desprovistos de cualquier poder para regular las actividades de las empresas transnacionales o para proteger los recursos nacionales: humanos o materiales frente a los desmanes del capital.

Los gobiemos serán tan sólo gerentes del gran capital, independientemente del signo político del partido que arribe al poder. Si un gobiemo realiza cualquier acción o política que tenga como resultado una disminución en las ganancias previstas por una empresa extranjera, ésta podrá quejarse ante su propio gobiemo, el cual podrá llevar al otro país ante un arbitraje internacional. $O$ bien, las empresas transnacionales podrán demandar directamente al gobiemo del país huésped ante un tribunal internacional. En cualquier caso, un grupo de especialistas en comercio tendrán la facultad de dar su fallo. De ser éste condenatorio para el país infractor, tendrá la obligación de compensar al capital demandante el "daño" infringido.

Dado el carácter mandante que sobre las naciones poseen los convenios y tratados intermacionales, de nada servirán los códigos laborales, las leyes de protección del ambiente, etc. Ninguna legislación nacional o política pública servirá frente a las garantías y derechos que se aseguran las empresas transnacionales con la promulgación de AMI.

Las políticas de desarrollo o de fomento a la microempresa, a la pequeña producción campesina, a los inversionistas nacionales, etc. serán consideradas como una actividad discriminatoria y atentatoria contra el principio de que "a ninguna empresa extranjera se le puede dar un trato menos favorable que el que se le concede a sus propios inversionislas". ¿Qué gobierno del tercer mundo se atreverá a delinear políticas de desarrollo luego de que cualquier empresa transnacional haya ganado su primera demanda?

Según el Acuerdo Multilateral de Inversiones (AMI), los países no pueden exigir a los inversionistas extranjeros que alcancen un determinado nivel de inversión en su territorio. Entre las condiciones que se prohíbe aplicar figuran las prescripciones relativas' al uso de abastecedores nacionales, a entrar en sociedad con empresas nacionales, o contratar una cantidad mínima de empleados locales. Estas medidas, que desde la perspectiva del Estado nacional pudieran acarrear algún beneficio, quedan vedadas con la aplicación del AMI y, en consecuencia, su implementación daría lugar a un reclamo judicial. Para colmo de males, cualquier gobiemo que firme el AMI tendrá que esperar al menos cinco años para denunciarlo $\mathrm{y} / \mathrm{o}$ revocarlo, $\mathrm{y}$ las inversiones hechas seguirán protegidas por las disposiciones del tratado neoimperialista, al menos durante 15 años más, con lo cual se le garantiza una vida útil al AMI arriba de los 20 años.

Con la aprobación del AMI saldrán afectados los trabajadores ${ }^{2}$, a quienes difícilmente se les permitirá realizar huelgas; los microempresarios, ya que no 
podrán aspirar a ningún trato preferente; los campesinos, que tendrán que competir en plano de igualdad con los agricultores del primer mundo; los pequeños y medianos empresarios, que tendrán que olvidarse de las políticas de fomento; los gobernantes, que verán reducido su poder, y, sobre todo, los grandes empresarios nacionales, para quienes ya no habrá políticas discriminatorias a favor de sus intereses de capital.

Sin embargo, no es remoto pensar que -como ha ocurrido con otras medidas neoliberales, muy acordes con la "onda" globalizadora- los diferentes sectores productivos, que polencialmenle pueden ser afectados, no acepten nuestros planteamientos y prefieran creerles a los "técnicos" de FUSADES, la AID, del Banco Interamericano de Desarrollo y del Banco Mundial.

No obstante, ante estas realidades del capitalismo mundial resulta hasta ofensiva la preocupación que muestran quienes quieren acceder al poder y las promesas de los candidatos que cínica, ingenua $o$ inconscientemente formulan a los electores; las apologías de la democracia que efeclúan otros sin tener clara conciencia del manejo opiáceo de sus palabras, y las denuncias en periódicos y revistas de los defensores del modelo neoliberal argumentando que el sistema sabe protegerse. Y para colmo de males, tanto los unos como los otros se atreven a descalificar los planteamientos de la izquierda —considerados desfasados, dogmáticos y poco autocríticos-, cuando en realidad son los únicos que se mantienen consecuentes al negar la viabilidad del sistema capitalista y buscar alternativas que ofrecer, a fin de mantener vivas las esperanzas, buscando demostrar que la utopía no ha muerto, aunque tan sólo sea porque se dibuja en las pupilas de los niños.

El sistema ha creado sus defensores voluntarios, además de los pagados de siempre, quienes se encargan de cuidar de que nadie venga a perturbar la deliciosa paz ganada con tanto esfuerzo y sacrificio por los difusos luchadores de la libertad. El cambalache es tal que Discepulos se quedó cortísimo con su tango.

Lo triste y lamentable de todo esto es que a medida que el capital no encuentra resistencias, lejos de humanizarse, como algunos tontamente creían que iba a suceder, ocurre todo lo contrario: el capital muestra con más saña loda su bestialidad y sus insaciables ansias de ganancia. Que ya dos tercios de la humanidad se encuentren hundidos en la pobreza, y otros en la más abyecta miseria, no parece preocuparle a los empresarios capitalistas.

Sus inquieludes y preocupaciones giran en torno a encontrar la forma de defenderse de los ataques previsibles de sus competidores, lo cual los está llevando a niveles de centralización del capital nunca antes vistos. Tales son los casos de absorciones o fusiones reportados recientemente: Travelers Corp con Citicorp, MCI Comunications con Worldcom, Bank America con Nations Bank, Chrysler Corp con Daimler-Benz, etc., transacciones que suman varios miles de 
millones de dólares y que afectan el trabajo y la vida de cientos de miles de personas.

Ante esta realidad terrible y que escapa al control de cualquier gobiemo, ya no digamos de cualquier organización de la sociedad civil, es bueno que tomemos conciencia del momento histórico en que vivimos, de nuestra responsabilidad en cuanto a la bestia que crearon nuestros ancestros y que nuestras generaciones han alimentado tan abundantemente, al punto de que acabará con la especie humana, si antes nosotros no acabamos con ella.

\section{Notas}

1. La bibliografía consultada fue "El Acuerdo Multilateral de Inversiones (AMI)", hoja informativa de la OCDE, y "Diez razones para estar preocupados", Amigos de la Tierra/FOE. Ambos se tomaron de Internet. Sc agradece a J.S. y a E.M.

2. "Curiosamente, los que deberían movilizarse más, los movimientos sindicales representados en el seno de la OCDE por las Confederaciones sindicales internacionales, se han limitado a proponer, evidentemente sin éxito, el añadido al AMl de una «ccláusula social >, en lugar de denunciar los propios fundamentos del acuerdo"; Wallach, Lori M., El nuevo “manifiesto”, Le Monde Diplomatique, febrero, 1998. 